\title{
Substance Use Among Patients Receiving Out- and Inpatient Dependence Care: a Prospective Norwegian Cohort Study From 2016 to 2020
}

\section{Jørn Henrik Vold ( $\square$ jorn.vold@uib.no)}

Universitetet i Bergen Det medisinsk-odontologiske fakultet https://orcid.org/0000-0001-8701-7638

\section{Fatemeh Chalabianloo}

University of Bergen Faculty of Medicine and Dentistry: Universitetet i Bergen Det medisinsk-odontologiske fakultet

\section{Christer F. Aas}

University of Bergen Faculty of Medicine and Dentistry: Universitetet i Bergen Det medisinsk-odontologiske fakultet

\section{Else-Marie Løberg}

Haukeland University Hospital: Haukeland Universitetssjukehus

\section{Kjell Arne Johansson}

University of Bergen: Universitetet i Bergen

\section{Lars Thore Fadnes}

University of Bergen Faculty of Medicine and Dentistry: Universitetet i Bergen Det medisinsk-odontologiske fakultet

\section{Research Article}

Keywords: Substance-related disorders, Substance use, inpatient detoxification, opiate substitution treatment, comorbidities, illicit drugs, low-threshold health services

Posted Date: June 2nd, 2021

DOI: https://doi.org/10.21203/rs.3.rs-566225/v1

License: @ (i) This work is licensed under a Creative Commons Attribution 4.0 International License. Read Full License 


\section{Abstract}

Background

Continuous use of amphetamines, alcohol, benzodiazepines, cannabis, cocaine, or opioids contributes to health impairments, increased morbidity, and overdose deaths among patients with substance use disorders (SUDs). This study evaluates the impact of inpatient detoxification, specialized opioid agonist therapy (OAT), and low-threshold municipality care on substance use over time.

\section{Methods}

We used data from a cohort of SUD patients in Norway through health assessments of self-reported substance use and sociodemographic and clinical factors. A total of 881 substance use measurements, including type and amount of substances, were assessed from 708 SUD patients in 2016-2020. Substance use for individual and total substances was calculated, creating a substance use severity index (SUSI) ranging from zero (no use) to one (daily use). We defined baseline as the first substance use measurement when the measurements were listed chronologically. Time was defined as years from baseline. We used a linear mixed model to analyze associations between the SUSI and inpatient detoxification, specialized OAT compared with low-threshold municipality care, as well as the factors like injecting substance use, gender, and age, presented with coefficients and $95 \%$ confidence intervals $(\mathrm{Cl})$.

Results

Neither inpatient detoxification (mean SUSI change: $0.01,-0.03 ; 0.04)$ nor specialized OAT $(0.03,-0.09 ; 0.14)$ compared with low-threshold municipality care were associated with changes in substance use over time. Patients who were over 60 years of age (mean SUSI difference: $-0.06,-0.13 ; 0.00$ ) had a lower SUSI than those under 30 years of age, while patients who injected substances had a higher SUSI than those who did not inject substances $(0.18,0.15 ; 0.20)$ at baseline. The mean SUSI for the individual substances were 0.50 (standard deviation (SD): 0.38) for cannabis, 0.40 (0.37) for benzodiazepines, $0.33(0.34)$ for amphetamines and cocaine, $0.31(0.29)$ for alcohol, and $0.22(0.31)$ for opioids at baseline. The mean SUSI of all substances was $0.35(0.20)$.

\section{Conclusion}

The present study demonstrates that neither inpatient detoxification nor specialized OAT compared to lowthreshold municipality care were associated with changes in substance use over time. Future research needs to evaluate the impact on substance use and healthy survival of multiple health care interventions to this patient group.

\section{Background}

More than half of patients with substance use disorders (SUDs) use addictive substances continuously while enrolled in care [1, 2]. Continuous substance use diminishes treatment effects and is associated with health adversities, morbidity, and overdose deaths [2, 3]. In 2020, the European Union presented a substance strategy 
for 2021-2025 to reduce the substance demand, dependence, and supply of substances and address the substance-related health and social by 2025 [4]. By this ambitious strategy, increased opioid agonist therapy (OAT) coverage is essential in preventing injecting opioid use [5], reducing premature mortality [6], and limiting illegal opioid consumption for patients with severe opioid dependence $[7,8]$. However, it is highly uncertain to what extent long-term specialized OAT and other treatment approaches - such as inpatient detoxification, low-threshold municipality care, and various specialized outpatient treatments - reduce the total substance use among SUD patients.

Patients with continuous substance use suffer from multiple disease burdens, and many have physical and mental comorbidities and socioeconomic difficulties [2]. Mental comorbidities - such as personality disorders, psychotic and affective disorders - are common [9-11]. Also, there is a high prevalence of hepatitis $\mathrm{C}$ virus (HCV) and human immunodeficiency virus (HIV) infections, endocarditis, and bacterial abscesses, caused by injecting substance use [12-16]. A chaotic life situation is presented in many cases involving unstable housing situations, unemployment, and disrupted family and social relationships. Additionally, continuous substance use constitutes a particular risk of non-fatal and fatal overdoses [15], typically when combining opioids with other sedative substances or alcohol [17]. The European Monitoring Centre of Drug and Drug Addiction has estimated a wide variance in percentages between $11 \%$ and $70 \%$ of OAT patients who use other substances than opioids [2]. This is almost similar percentages for the Europeans with harmful opioid use [18].

Inpatient detoxification, specialized OAT, and low-threshold municipality care may be steps toward rehabilitation and recovery from continuous substance use. Inpatient detoxification usually involves medical and psychosocial follow-ups targeting a range of physical and mental substance withdrawal symptoms, e.g., nausea, tremors, sweating, irritability, insomnia, hallucinations, seizures, and anxiety [19]. However, studies have shown that relapse to substance use is common, and few remain long-term abstinent [20-23]. Furthermore, low-threshold municipality care and specialized OAT involving integrated and multidisciplinary teams lack evidence on their impact on substance use changes in SUD populations [24, 25].

Thus, the present study's objectives are to evaluate the continuous substance use in terms of type and amount of consumed substances, including benzodiazepines, cannabis, opioids, amphetamines and cocaine, and alcohol over time among Norwegian patients in care for substance use disorders (SUD) using a substance use severity index. In addition, we aim to assess three treatment approaches and injecting substance use and how these are associated with changes in substance use over time. More specifically, we will:

1. calculate the substance use at baseline and assess changes over time.

2. evaluate the injecting substance use, inpatient detoxification, and specialized opioid agonist therapy (OAT) compared with low-threshold municipality care's impact on the substance use.

\section{Methods}

\subsection{Data source}


We used data from a cohort nested to the INTRO-HCV study in Bergen and Stavanger, Norway [26]. Data were collected from May 2016 to July 2020, and patients were recruited from specialized OAT outpatient clinics in Bergen and Stavanger and from municipality health care clinics underlying the Bergen Municipality.

\subsection{Data collections}

All included patients were assessed yearly concerning physical and mental health status, current substance use, and sociodemographic and clinical data. The data were amassed in a health register using electronic data collection software (Checkware) under research nurses' supervision. All the clinical data, including OAT medication (buprenorphine- or methadone-based medication), educational level, inpatient detoxifications, specialized OAT, low-threshold municipality care, severe infectious diseases (HCV, hepatitis B virus, and HIV infections), and substance use were collected from the electronic medical record.

\subsection{Study sample}

We included 881 self-reported substance use measurements from 708 patients with SUDs in the study period. Of those, 171 patients had more than one substance use measurements, providing 346 repeated measurements. The median time interval between the first health assessments (baseline), and any subsequent assessments in the same patients, including substance use measurements, was 16 months (interquartile range (IQR): 13-20).

\subsection{Measuring substance use}

We measured substance use during the past 12 months prior to the assessments using a Likert scale ranging from zero (no use) to six points (daily use) for each substance class, including cannabis, opioids (opioids received in OAT were not included), stimulants (amphetamines or cocaine), benzodiazepines, and alcohol. The substance scores (0-5) were handled separately for each substance class and were additionally summarized as a sum score ranging from zero to 25 points (Additional File 1). Furthermore, the scores were standardized into a continuous SUSI ranging from zero (no use) to one (daily use) by dividing the total substance sum score by five (for individual substance class) or 25 (for all substance classes). The data collection software only allowed valid responses to each substance and prompted empty questions before submission to minimize missing data.

\subsection{Assessing severe infectious diseases}

We assessed the extent of severe infectious diseases as the markers of the study populations' comorbidities. Thus, we collected blood samples, including hepatitis B surface antigen, HIV antigens/antibodies, and HCV polymerase chain reaction, during health assessments. Blood samples were analyzed at the Department of Laboratory Medicine, Haukeland University Hospital, Bergen, Norway, and the Department of Medical Biochemistry and Microbiology, Stavanger University Hospital, Stavanger, Norway (accredited by ISO-standard 15189).

\subsection{Definition of study variables}

We defined baseline for patients as the first health assessment that included a substance use measurement when we listed the health assessments chronologically. The age was classified into five groups: 18-30, 30$40,40-50,50-60$, and $\geq 60$. We defined being in OAT according to whether patients received buprenorphine 
or methadone (OAT opioids) or not at baseline. We set 'injecting substance use' as having injected at least once at any time during the past six months prior to the health assessment. Having chronic infectious diseases was defined as detecting HCV RNA by polymerase chain reaction, hepatitis B virus surface antigen, or HIV antigen/antibodies in the blood samples. Additionally, we defined inpatient detoxifications as being hospitalized for detoxification at least once between baseline and the last substance use measurement. The duration of inpatient detoxification was not considered. Furthermore, "specialized OAT" and "low-threshold municipality care" were defined according to the locations for the health assessments. The "low-threshold municipality care" served basal medical and psychosocial support, including activities and food supply, for marginalized SUD patients, while SUD patients with severe opioid dependence received specialized OAT involving at least weekly deliveries of OAT opioids and medical and psychosocial support performed by multidisciplinary teams, including consultant in addiction medicine, phycologist, nurses, and social workers.

\subsection{Statistical analyses}

We used Stata/SE 17.0 (StataCorp, TX, USA) for descriptive and linear mixed model analyses. Sankeymatic (sankeymatic.com) was used for the generation of a Sankey diagram for graphical presentation of the change in the use of substances over time. The threshold for statistical significance was set to $P<0.05$ for all analyses unless otherwise stated. In all analyses, we defined time as years from baseline.

Linear mixed model analyses were used to investigate whether the treatment approaches, injecting substance use, age, and gender affected the SUSI at baseline and to what extent they influenced any changes in the SUSI from baseline to the following health assessments. We specified the linear mixed models as a random intercept fixed slope regression model. The estimator was set to Restricted Maximum Likelihood. The predictors were handled both as constant baseline variables and as time-varying variables over time, with the SUSI as the outcome variable. The full information maximum likelihood ensured that all available substance use measurements were used.

\subsection{Ethics approval and consent to participate}

The study is reviewed and approved by the Regional Ethical Committee for Health Research West, Norway (REK Vest 2017/51). Each patient provided written informed consent prior to enrolling in the study.

\section{Results}

\subsection{Patients' characteristics at baseline}

Seventy-three percent of the study sample were males, and the mean age was 43 years (standard deviation (SD): 11 years) at baseline (Table 1). Six percent had not completed primary school, and $44 \%$ had primary school as their highest educational level. Fifty-four percent injected substances during the past six months leading up to the substance use measurement, and $20 \%$ of patients were admitted to at least one inpatient detoxification in the time between baseline and the last health assessment. Ninety-six percent had consumed at least one substance during the past 12 months before the first health assessment. 
The mean SUSI for all the substances was 0.35 (SD: 0.20) (Table 2). Cannabis was the substance most frequently used (mean score: $0.50(0.38)$ ), followed by benzodiazepines $(0.40(0.37))$, stimulants $(0.33(0.34))$, alcohol (0.31 (0.29)), and opioids (0.22 (0.31)).

3.3. The associations between the substance use severity index and treatment approaches, age, gender, and injecting substance use at baseline

Patients who received low-threshold municipality care were associated with a higher SUSI than those who received the specialized OAT (mean SUSI difference: $0.07,95 \%$ confidence interval: $0.04 ; 0.10$ ). Furthermore, patients over 60 years of age $(-0.06,-0.13 ; 0.00)$ had lower SUSI than those under 30 (Table 3), while patients who inject substances had a higher SUSI compared to those who did not inject $(0.18,0.15 ; 0.20)$.

\subsection{The associations between the substance use severity index and treatment approaches, and injecting substance use over time}

No changes in the SUSI were found when comparing low-threshold municipality care with the specialized OAT from baseline until the end of the study period (mean SUSI change: $0.03,95 \% \mathrm{Cl}:-0.09 ; 0.14$ ). Likewise, patients admitted to the inpatient detoxification did not show changes in the SUSI over time compared with those not admitted to inpatient detoxification $(0.01,-0.03 ; 0.04)$. However, the SUSI increased among patients who started to inject substances from baseline compared with those who did not start to inject $(0.11$, $0.07 ; 0.15)$. Overall, the SUSI did not change substantially over time in this SUD population $(-0.02,-0.04 ; 0.00)$, although some intra-individual substance use changes were found (Fig. 1).

\section{Discussion}

The present study has revealed considerable substance use among SUD patients enrolled in care. Patients who received low-threshold municipality care had higher substance use than those who received specialized OAT at baseline, probably because OAT opioids were not included in the SUSI. Neither inpatient detoxification nor specialized OAT compared with low-threshold municipality care were associated with changes in substance use. Patients over 60 years of age had lower substance use than patients under 30 years of age at baseline, and higher substance use was found among patients who injected substances at baseline and those who started to inject after baseline. Overall, cannabis was the most prevalent substance used, followed by alcohol, benzodiazepines, stimulants, and opioids. The adjusted SUSI remained substantially unchanged over time in this population.

The substance use levels were high among patients undergoing specialized OAT and those receiving lowthreshold municipality care, with levels exceeding prevalence estimates of benzodiazepine and stimulant use in the national data on the OAT population in Norway [27]. Additionally, the benzodiazepine prevalence estimate reached the upper part of the estimates in European countries among harmful opioid users, ranging from $45 \%$ to $70 \%$ [18]. Higher availability of illegal substances and a consequently higher number of SUD patients in bigger cities than in other regions could be a possible reason for these findings.

There was no association between substance use before and after inpatient detoxification. This indicates that reducing substance use does not seem to be the outcome of inpatient detoxification care. However, other 
indirect effects of detoxification could occur. Most SUD patients were marginalized substance users with different aspects of health and social problems, in addition to the current SUDs, which needed to be addressed during inpatient detoxification [3]. Thus, inpatient detoxification should be one of several approaches in a comprehensive treatment course for these patients. Nevertheless, reducing substance use may be difficult, and relapse to substance use may even be expected for many of these patients. A previous study found that younger patients, patients having a psychiatric diagnosis, and those receiving short-term (two-four months) compared with long-term (> six months) SUD treatment were at particular risk for relapsing after inpatient SUD treatment [20]. In the present study, many patients met at least one of these risk factors, which might be the reasons for our findings. Another factor may be that inpatient detoxifications primarily aimed to stabilize the patient and improve follow-up care without reducing substance use. If this is the case, the treatment went under the wrong heading and should instead be classified as a form of stabilization. Other outcome measures of their effectiveness may be thus needed.

The specialized OAT and the low-threshold municipality care had similar and low impacts on substance use. Although being in specialized OAT is well-documented in reducing illegal and injecting opioid use and opioidrelated overdose deaths compared with it before OAT [5-8], to our knowledge, no studies have evaluated the impact of ongoing OAT on total substance use over time. Our findings showed unchanged substance use levels, which were in line with the trends of national substance use and prescribed potentially addictive substances in the OAT population during 2015-2017 [27-30]. On the other hand, the present study only included patients who had received specialized OAT over several years, which means that the substance use changes before entering specialized OAT or low-threshold municipality care were not considered. Nevertheless, identifying treatment approaches that reduce the use of other substances is essential for successful rehabilitation and for protecting against relapse to illegal opioid use for patients undergoing specialized OAT [6, 31]. Likewise, low-threshold municipality care, including medical and psychosocial followups, activities, and food supply, may be essential in creating relationships between patients and health professionals to encourage substance use change and prevent fatal and non-fatal overdose deaths. The present study was not designed to demonstrate causal relationships. Evaluating new approaches - such as long-term tapering off from some substances like benzodiazepines [32] and integrated treatment care [3335], within existing treatment approaches might be one of several keys to reduce substance use in this population in the future.

Injecting substance users showed a higher rate of substance use than those who did not inject. According to previous studies [36,37], it is also likely that high substance use predicts injecting substance use in this population. Injecting substances are associated with dependences and a wide range of health harms [2,38], resulting in overdoses and hospital admissions [38]. The broad range of comorbidities and complexity among injecting substance users signifies the need for coordinated medical and psychosocial health care to reduce substance use in line with the European Union's Drug Strategy for 2021-2025 [4]. Thus, various treatment approaches may be important in recovering these patients for injecting substance use and taking care of the complex medical and psychosocial comorbidities [33].

Age over 60 years was substantially associated with lower substance use than those under 30 years of age. This corresponds to previous reports $[39,40]$. Older SUD patients usually have more substance-related physical and mental comorbidities than younger, placing a higher responsibility on existing health care 
services. Previous observational studies have shown that receiving health services and being older were associated with more legal prescriptions of addictive medications to older patients compared to younger ones, perhaps intending to make their illegal substance use less likely [28, 41, 42]. This might explain the lower substance use among older than younger SUD patients. On the other hand, one can assume that SUD patients who have reached 60 years of age generally have fewer substance dependences and a lower risk of dying in overdose accidents. In $2017,59 \%$ of premature deaths from substance overdose were among those younger than 50 years globally [43], which may give evidence that those with the most extensive substance use die before reaching 60 .

\section{Strengths And Limitations}

This study has some strengths and limitations. We have included 708 SUD patients that usually are difficult to reach in health care. Of those, 171 patients had follow-up measurements at least in one year, making longitudinal analyses possible. However, these results should be interpreted cautiously because they only represented one out of four recruited patients. Three out of four patients were mainly recruited from specialized OAT outpatient clinics, which could affect the generalizability of our results to other SUD populations. Due to clinical challenges, including systematic and patient delays, the health assessments were conducted at varying time intervals. This may slightly complicate the interpretation of the predicted substance use changes from baseline. Moreover, the duration for inpatient detoxification and the time intervals between substance use measurements and inpatient detoxification were not considered in the analyzes, which may reduce the results' generalizability. Furthermore, the substance use changes were only estimated for patients who underwent specialized OAT or low-threshold municipality care over time, which means that the impact of entering specialized OAT or low-threshold municipality care in comparison to the time before those was not considered. Furthermore, more frequent substance use measurements could have identified possible fluctuations within shorter time intervals that might not necessarily be prolonged. Still, our estimates are likely to have captured the general patterns.

\section{Conclusion}

Neither inpatient detoxification nor specialized OAT compared with low-threshold municipality treatment were associated with changes in substance use over time. However, reduction in substance use is only one of many goals of SUD care and treatments. Future research needs to evaluate the impact on substance use, and other key outcomes of a range of treatment approaches, including integrated methods, ideally in randomized controlled trials.

\section{Abbreviations}

Cl: Confidence Interval

HCV: Hepatitis C Virus

HIV: Human Immunodeficiency Virus 
IQR: Interquartile Range

OAT: Opioid Agonist Therapy

SD: Standard Deviation

SUSI: Substance Use Severity Index

SUD: Substance Use Disorder

\section{Declaration}

\section{Ethics approval and consent to participate}

The study has been reviewed and approved by the Regional Ethical Committee for Health Research (REC) West, Norway (reference number: 2017/51/REK Vest, dated 29.03.2017/20.04.2017). Each patient provided written informed consent prior to enrolling in the study.

Consent for publication

Participants have consented for publication

Availability of data and material

No additional data are available due to data protection requirements.

Competing interests

Not applicable

\section{Funding}

This work was supported by The Norwegian Research Council (BEHANDLING, contract no 269855) and the Western Norway Regional Health Authority («Åpen prosjektstøtte») with the Department of Addiction Medicine, Haukeland University Hospital, Bergen, Norway as responsible institution. The funders had no role in the study design, data collection and analysis, decision to publish, or preparation of the manuscript. Two of the authors are funded from the research grant BEHANDLING related to the project INTRO-HCV from the Norwegian Research Council. The other authors are funded by their respective affiliations.

\section{Authors' contributions}

JHV have led the study design, analysis, and article preparation. FC, CFA, EML, KAJ, and LTF have contributed in the article preparation. All authors have read and approved the final article.

Acknowledgements

We thank Nina Elisabeth Eltvik and Christer Kleppe for their valuable help and input during the planning and preparation phases. We also thank the INTRO-HCV Study Group for important contribution relating to data 
collection.

INTRO-HCV Study Group participating investigators:

Bergen: Christer Frode Aas, Vibeke Bråthen Buljovcic, Fatemeh Chalabianloo, Jan Tore Daltveit, Silvia Eiken Alpers, Lars T. Fadnes (principal investigator), Trude Fondenes Eriksen, Per Gundersen, Velinda Hille, Kristin Holmelid Håberg, Kjell Arne Johansson, Rafael Alexander Leiva, Siv-Elin Leirvåg Carlsen, Martine Lepsøy Bonnier, Lennart Lorås, Else-Marie Løberg, Mette Hegland Nordbotn, Cathrine Nygård, Maria Olsvold, Christian Ohldieck, Lillian Sivertsen, Hugo Torjussen, Jørn Henrik Vold, Jan-Magnus Økland

Stavanger: Tone Lise Eielsen, Nancy Laura Ortega Maldonado, Ewa Joanna Wilk

proLAR: Ronny Bjørnestad, Ole Jørgen Lygren, Marianne Cook Pierron

Oslo: Olav Dalgard, Håvard Midgard, Svetlana Skurtveit

Bristol: Aaron G. Lim, Peter Vickerman

\section{References}

1. Results from the 2018 National Survey on Drug Use and Health: Detailed Tables. In., vol. Rockville, Maryland, August 2019: United States, Substance Abuse and Mental Health Services Administration, Center for Behavioral Health Statistics and Quality; 2019.

2. European Monitoring Centre for D, Drug A: Polydrug use : patterns and responses. Luxembourg: Luxembourg : Publications Office of the European Union; 2009.

3. World Drug Report 2020, booklet 4. In. https://wdr.unodc.org/uploads/wdr2020/documents/WDR20_BOOKLET_4.pdf (downloaded: March, 26, 2021): United Nations Office on Drugs and Crime; 2020.

4. The European Union Drug Strategy 2021-25. In. https://data.consilium.europa.eu/doc/document/ST14178-2020-INIT/en/pdf (downloaded May 4, 2021): Euroepan Union; 2020.

5. Lawrinson P, Ali R, Buavirat A, Chiamwongpaet S, Dvoryak S, Habrat B, Jie S, Mardiati R, Mokri A, Moskalewicz $\mathrm{J}$ et al: Key findings from the WHO collaborative study on substitution therapy for opioid dependence and HIV/AIDS. Addiction 2008, 103(9):1484-1492.

6. Sordo L, Barrio G, Bravo MJ, Indave BI, Degenhardt L, Wiessing L, Ferri M, Pastor-Barriuso R: Mortality risk during and after opioid substitution treatment: systematic review and meta-analysis of cohort studies. BMJ 2017, 357:j1550.

7. Nielsen S, Larance B, Degenhardt L, Gowing L, Kehler C, Lintzeris N: Opioid agonist treatment for pharmaceutical opioid dependent people. Cochrane Database Syst Rev 2016(5):Cd011117.

8. Mattick RP, Breen C, Kimber J, Davoli M: Methadone maintenance therapy versus no opioid replacement therapy for opioid dependence. Cochrane Database Syst Rev 2009, 2009(3):Cd002209.

9. Armstrong TD, Costello EJ: Community studies on adolescent substance use, abuse, or dependence and psychiatric comorbidity. J Consult Clin Psychol 2002, 70(6):1224-1239. 
10. Mueser KT, Gottlieb JD, Cather C, Glynn SM, Zarate R, Smith LF, Clark RE, Wolfe R: Antisocial Personality Disorder in People with Co-Occurring Severe Mental Illness and Substance Use Disorders: Clinical, Functional, and Family Relationship Correlates. Psychosis 2012, 4(1):52-62.

11. Ross S, Peselow E: Co-occurring psychotic and addictive disorders: neurobiology and diagnosis. Clin Neuropharmacol 2012, 35(5):235-243.

12. World Health O: Global hepatitis report 2017. Geneva: World Health Organization; 2017.

13. World Drug Report 2020, booklet 2. In. https://wdr.unodc.org/uploads/wdr2020/documents/WDR20_Booklet_2.pdf (downloaded: April, 6, 2021): United Nations Office on Drugs and Crime; 2020.

14. Aas CF, Vold JH, Skurtveit S, Odsbu I, Chalabianloo F, Lim AG, Johansson KA, Fadnes LT: Uptake and predictors of direct-acting antiviral treatment for hepatitis $\mathrm{C}$ among people receiving opioid agonist therapy in Sweden and Norway: a drug utilization study from 2014 to 2017. Subst Abuse Treat Prev Policy 2020, 15(1):44.

15. Drug-related deaths and mortality in Europe - Update from the EMCDDA expert network. In. https://www.emcdda.europa.eu/system/files/publications/11485/20193286_TD0319444ENN_PDF.pdf (Downloaded April 4, 2021): European Monitoring Centre for Drugs and Drug Addiction; 2019.

16. Aas CF, Vold JH, Skurtveit S, Odsbu I, Chalabianloo F, Økland JM, Leiva RAM, Vickerman P, Johansson KA, Fadnes LT: On the path towards universal coverage of hepatitis $C$ treatment among people receiving opioid agonist therapy (OAT) in Norway: a prospective cohort study from 2013 to 2017. BMJ Open 2020, 10(8):e036355.

17. Tori ME, Larochelle MR, Naimi TS: Alcohol or Benzodiazepine Co-involvement With Opioid Overdose Deaths in the United States, 1999-2017. JAMA Netw Open 2020, 3(4):e202361.

18. Perspectives on drugs: The misuse of benzodiazepines among high-risk opioid users in Europe. In. https://www.emcdda.europa.eu/system/files/publications/2733/Misuse\%20of\%20benzos_POD2015.pdf (dated: January 28, 2021): European Monitoring Centre for Drugs and Drug Addiction; 2018.

19. World Health Organization. Regional Office for the Western P: Clinical guidelines for withdrawal management and treatment of drug dependence in closed settings: Manila : WHO Regional Office for the Western Pacific; 2009.

20. Andersson HW, Wenaas M, Nordfjærn T: Relapse after inpatient substance use treatment: A prospective cohort study among users of illicit substances. Addict Behav 2019, 90:222-228.

21. Oppenheimer E, Tobutt C, Taylor C, Andrew T: Death and survival in a cohort of heroin addicts from London clinics: a 22-year follow-up study. Addiction 1994, 89(10):1299-1308.

22. Strang J, McCambridge J, Best D, Beswick T, Bearn J, Rees S, Gossop M: Loss of tolerance and overdose mortality after inpatient opiate detoxification: follow up study. Bmj 2003, 326(7396):959-960.

23. Wines JD, Jr., Saitz R, Horton NJ, Lloyd-Travaglini C, Samet JH: Overdose after detoxification: a prospective study. Drug Alcohol Depend 2007, 89(2-3):161-169.

24. Jeal N, Macleod J, Turner K, Salisbury C: Systematic review of interventions to reduce illicit drug use in female drug-dependent street sex workers. BMJ Open 2015, 5(11):e009238. 
25. CHAPTER 4, EARLY INTERVENTION, TREATMENT, AND MANAGEMENT OF SUBSTANCE USE DISORDERS. Substance Abuse and Mental Health Services Administration (US); Office of the Surgeon General (US) Facing Addiction in America: The Surgeon General's Report on Alcohol, Drugs, and Health [Internet]. Washington (DC): US Department of Health and Human Services; 2016 Nov.

26. Fadnes LT, Aas CF, Vold JH, Ohldieck C, Leiva RA, Chalabianloo F, Skurtveit S, Lygren OJ, Dalgård O, Vickerman $P$ et al: Integrated treatment of hepatitis $\mathbf{C}$ virus infection among people who inject drugs: study protocol for a randomised controlled trial (INTRO-HCV). BMC Infect Dis 2019, 19(1):943.

27. Lobmaier P, Skeie I, Lillevold P, Waal H, Bussesund K, Clausen T: LAR statusrapport 2019 - nye medisiner nye muligheter? In.

https://www.med.uio.no/klinmed/forskning/sentre/seraf/publikasjoner/rapporter/2020/seraf-rapport-nr1-2020-statusrapport-2019.pdf (dated: January 28, 2021): The Norwegian Centre for Addiction Research (Norwegian: Senter for rus- og avhengighetsforskning (SERAF)); 2020.

28. Vold JH, Skurtveit S, Aas C, Chalabianloo F, Kloster PS, Johansson KA, Fadnes LT: Dispensations of benzodiazepines, z-hypnotics, and gabapentinoids to patients receiving opioid agonist therapy; a prospective cohort study in Norway from 2013 to 2017. BMC Health Serv Res 2020, 20(1):352.

29. Vold JH, Aas C, Skurtveit S, Odsbu I, Chalabianloo F, Reutfors J, Halmøy A, Johansson KA, Fadnes LT: Potentially addictive drugs dispensing to patients receiving opioid agonist therapy: a register-based prospective cohort study in Norway and Sweden from 2015 to 2017. BMJ Open 2020, 10(8):e036860.

30. Vold JH, Skurtveit S, Aas C, Johansson KA, Fadnes LT: Too much or too little opioids to patients receiving opioid agonist therapy in Norway (2013-2017): a prospective cohort study. BMC Health Serv Res 2020, 20(1):668.

31. Guidelines for the Psychosocially Assisted Pharmacological Treatment of Opioid Dependence. In. https://apps.who.int/iris/bitstream/handle/10665/43948/9789241547543_eng.pdf?sequence=1 (dated: January 31, 2021): World Health Organization; 2009.

32. Ribeiro PRS, Schlindwein AD: Benzodiazepine deprescription strategies in chronic users: a systematic review. Fam Pract 2021.

33. Donald M, Dower J, Kavanagh D: Integrated versus non-integrated management and care for clients with co-occurring mental health and substance use disorders: a qualitative systematic review of randomised controlled trials. Soc Sci Med 2005, 60(6):1371-1383.

34. Vold JH, Aas C, Leiva RA, Vickerman P, Chalabianloo F, Løberg EM, Johansson KA, Fadnes LT: Integrated care of severe infectious diseases to people with substance use disorders; a systematic review. BMC Infect Dis 2019, 19(1):306.

35. Fadnes LT, Aas CF, Vold JH, Leiva RA, Ohldieck C, Chalabianloo F, Skurtveit S, Lygren OJ, Dalgård O, Vickerman $\mathrm{P}$ et al: Integrated treatment of hepatitis $\mathrm{C}$ virus infection among people who inject drugs: $\mathrm{A}$ multi-center randomized controlled trial (INTRO-HCV). PLOS Med (accepted) 2021.

36. Dinwiddie SH, Cottler L, Compton W, Abdallah AB: Psychopathology and HIV risk behaviors among injection drug users in and out of treatment. Drug Alcohol Depend 1996, 43(1-2):1-11.

37. Roy É, Arruda N, Bruneau J, Jutras-Aswad D: Epidemiology of Injection Drug Use: New Trends and Prominent Issues. Can J Psychiatry 2016, 61(3):136-144. 
38. Trends in injecting drug use in Europe. In. https://www.emcdda.europa.eu/system/files/publications/614/EMCDDA_SI10_injecting_217651.pdf (downloaded April 8, 2021): European Monitoring Centre for Drugs and Drug Addiction; 2010.

39. Results from the 2018 National Survey on Drug Use and Health: Detailed tables. In. Rockville, MD: Center for Behavioral Health Statistics and Quality, Substance Abuse and Mental Health Services Administration. Retrieved from https://www.samhsa.gov/data/: Substance Abuse and Mental Health Services Administration; 2019.

40. Lipari RN, Van Horn SL: Trends in Substance Use Disorders Among Adults Aged 18 or Older. In: The CBHSQ Report. edn. Rockville (MD): Substance Abuse and Mental Health Services Administration (US); 2013: 1-10.

41. Beynon C, Stimson G, Lawson E: Illegal drug use in the age of ageing. Br J Gen Pract 2010, 60(576):481482.

42. Bakker A, Streel E: Benzodiazepine maintenance in opiate substitution treatment: Good or bad? A retrospective primary care case-note review. J Psychopharmacol 2017, 31(1):62-66.

43. Global Burden of Disease Study 2017 (GBD 2017). In. http://ghdx.healthdata.org/gbd-results-tool (downloaded: April 10, 2021): Seattle, United States: Institute for Health Metrics and Evaluation (IHME), Global Burden of Disease Collaborative Network. ; 2018.

\section{Tables}


Basic characteristics at baseline for all patients and for patients with more than one substance use measurement (numbers ( $\mathrm{n}$ ) and percentages (\%)):

\begin{tabular}{|c|c|c|}
\hline & $\begin{array}{l}\text { All } \\
\text { patients } \\
(\mathrm{N}= \\
708)\end{array}$ & $\begin{array}{l}\text { Patients with } \\
>1 \text { substance use } \\
\text { measurement } \\
(\mathrm{N}=171)\end{array}$ \\
\hline \multicolumn{3}{|l|}{ Age (years), n (\%) } \\
\hline $18-30$ & $84(12)$ & $11(6)$ \\
\hline $30-40$ & $204(29)$ & $43(25)$ \\
\hline $40-50$ & $215(30)$ & $57(33)$ \\
\hline $50-60$ & $164(23)$ & $47(27)$ \\
\hline$\geq 60$ & $41(6)$ & $13(8)$ \\
\hline Mean (SD) & $43(11)$ & $46(10)$ \\
\hline \multicolumn{3}{|l|}{ Gender, n (\%) } \\
\hline Male & $514(73)$ & $130(76)$ \\
\hline Female & $194(27)$ & $41(24)$ \\
\hline \multicolumn{3}{|l|}{ Highest educational level, n (\%) } \\
\hline Not completed primary school & $39(6)$ & $11(6)$ \\
\hline Completed primary school (9 years) & $306(44)$ & $77(45)$ \\
\hline Completed high school (12 years) & $277(40)$ & $66(39)$ \\
\hline$\leq 3$ years of college or university & $58(8)$ & $<15(<10)$ \\
\hline$>3$ years of college or university & $14(2)$ & $<15(<10)$ \\
\hline Injected substances during the past six months, $\mathrm{n}(\%)$ & $384(54)$ & $82(48)$ \\
\hline $\begin{array}{l}\left.\text { Unstable housing situation during the past } 30 \text { days }^{1}\right), n \\
(\%)\end{array}$ & $86(12)$ & $5(4)$ \\
\hline \multicolumn{3}{|l|}{ Substance used during the past 12 months $\left.{ }^{2}\right), \mathrm{n}(\%)$} \\
\hline Alcohol & $513(72)$ & $113(66)$ \\
\hline \multicolumn{3}{|l|}{ SD: Standard deviation. } \\
\hline \multicolumn{3}{|c|}{$\begin{array}{l}\text { 1) An unstable housing situation was defined as living in a homeless shelter, with family or friends at any } \\
\text { time during the past } 30 \text { days. Having owned or rented housing situation or being imprisoned were definec } \\
\text { as a stable housing situation. }\end{array}$} \\
\hline
\end{tabular}




\begin{tabular}{|c|c|c|}
\hline & $\begin{array}{l}\text { All } \\
\text { patients } \\
(\mathrm{N}= \\
708)\end{array}$ & $\begin{array}{l}\text { Patients with } \\
>1 \text { substance use } \\
\text { measurement } \\
(\mathrm{N}=171)\end{array}$ \\
\hline Benzodiazepines & $489(69)$ & $126(74)$ \\
\hline Cannabis & $537(76)$ & $133(78)$ \\
\hline Opioids & $344(49)$ & $75(44)$ \\
\hline Stimulants (amphetamines and cocaine) & $451(64)$ & $103(60)$ \\
\hline Inpatient detoxification, $\mathrm{n}(\%)$ & - & $35(20)$ \\
\hline Specialized OAT, n (\%) & $553(78)$ & $166(97)$ \\
\hline Low-threshold municipality care, $\mathrm{n}(\%)$ & $155(22)$ & $5(3)$ \\
\hline \multicolumn{3}{|l|}{ Comorbidities, n (\%) } \\
\hline Hepatitis C virus infection & $349(60)$ & $89(57)$ \\
\hline Hepatitis B virus infection & $5(<1)$ & $<5(<5)$ \\
\hline Human immunodeficiency virus & $<5(<5)$ & $<5(<5)$ \\
\hline \multicolumn{3}{|l|}{ SD: Standard deviation. } \\
\hline \multicolumn{3}{|c|}{$\begin{array}{l}\text { 1) An unstable housing situation was defined as living in a homeless shelter, with family or friends at any } \\
\text { time during the past } 30 \text { days. Having owned or rented housing situation or being imprisoned were defined } \\
\text { as a stable housing situation. }\end{array}$} \\
\hline
\end{tabular}


Table 2

The Substance Use Severity Index (SUSI) (mean (SD)) at baseline and follow-up

\begin{tabular}{|c|c|c|c|}
\hline & $\begin{array}{l}\text { Baseline }{ }^{1)} \\
(\mathrm{N}=708)\end{array}$ & $\begin{array}{l}\left.\text { Baseline }^{2}\right) \\
(\mathrm{N}=171)\end{array}$ & $\begin{array}{l}\text { Follow-up })^{3)} \\
(\mathrm{N}=171)\end{array}$ \\
\hline Alcohol & $0.31(0.29)$ & $0.29(0.29)$ & $0.28(0.27)$ \\
\hline Cannabis & $0.50(0.38)$ & $0.51(0.38)$ & $0.50(0.40)$ \\
\hline Benzodiazepines & $0.40(0.37)$ & $0.42(0.36)$ & $0.39(0.34)$ \\
\hline Opioids & $0.22(0.31)$ & $0.21(0.31)$ & $0.14(0.23)$ \\
\hline Stimulants (amphetamines and cocaine) & $0.33(0.34)$ & $0.28(0.31)$ & $0.25(0.31)$ \\
\hline All substances & $0.35(0.20)$ & $0.34(0.18)$ & $0.31(0.18)$ \\
\hline \multicolumn{4}{|c|}{ 1)The SUSI for all included patients at baseline } \\
\hline \multicolumn{4}{|c|}{${ }^{2)}$ The SUSI for patients with two or more substance use measurements at baseline } \\
\hline \multicolumn{4}{|c|}{$\begin{array}{l}\text { 3) The SUSI for patients with two or more substance use measurements on the last substance use } \\
\text { assessment during the study period. }\end{array}$} \\
\hline \multicolumn{4}{|c|}{$\begin{array}{l}\text { Each substance class and the total substance use ("All substances") are standardized using the SUSI } \\
\text { ranging from } 0 \text { to } 1 \text {, where } 0 \text { indicates no use and } 1 \text { indicates daily use of all substances (alcohol, } \\
\text { cannabis, benzodiazepines, opioids, and stimulants). SD: standard deviation. }\end{array}$} \\
\hline
\end{tabular}


Adjusted linear mixed model for the Substance Use Severity Index (SUSI) ${ }^{1)}(\mathrm{N}=706)$

\section{Effect estimates}

\section{Coefficients (95 \% Cl)}

Substance Use Severity Index $\left(\beta_{0}\right)$

Time trend

Baseline

Female

Years of age:

$<30$

$30-40$

$40-50$

$50-60$

$\geq 60$

Injecting substance use

Treatment:

Specialized OAT

Low-threshold Municipality Care

Predictors remain constant from baseline ${ }^{2)}$

Injecting substance use

$0.01(-0.02 ; 0.05)$

Treatment:

Specialized OAT

Low-threshold Municipality Care

0.00 (ref.)

$0.03(-0.09 ; 0.14)$

Time-varying predictors from baseline ${ }^{3)}$

Inpatient detoxification

$0.01(-0.03 ; 0.04)$

Starting to inject substances

$0.11(0.07 ; 0.15)$

OAT: Opioid agonist therapy.

1) The SUSI is a continuous variable ranging from 0 to 1 , where 0 indicates no substance use and 1 indicates daily substance use for all substances (cannabis, amphetamines, cocaine, opioids, benzodiazepines, and alcohol).

2) Interpretation: An estimation of the SUSI changes when the predictors remain constant from baseline (e.g., ongoing injecting substance use leads to no changes in the SUSI from baseline.)

3) Interpretation: An estimation of the SUSI changes when the predictors vary over time from baseline (e.g., going to inpatient detoxification or starting to inject substances from baseline).

The table displays a linear mixed model analysis (Restricted Maximum Likelihood regression) evaluating various treatment approaches, injecting substance use, age and gender's impact on the SUSI changes at baseline and over time. 


\section{Figures}

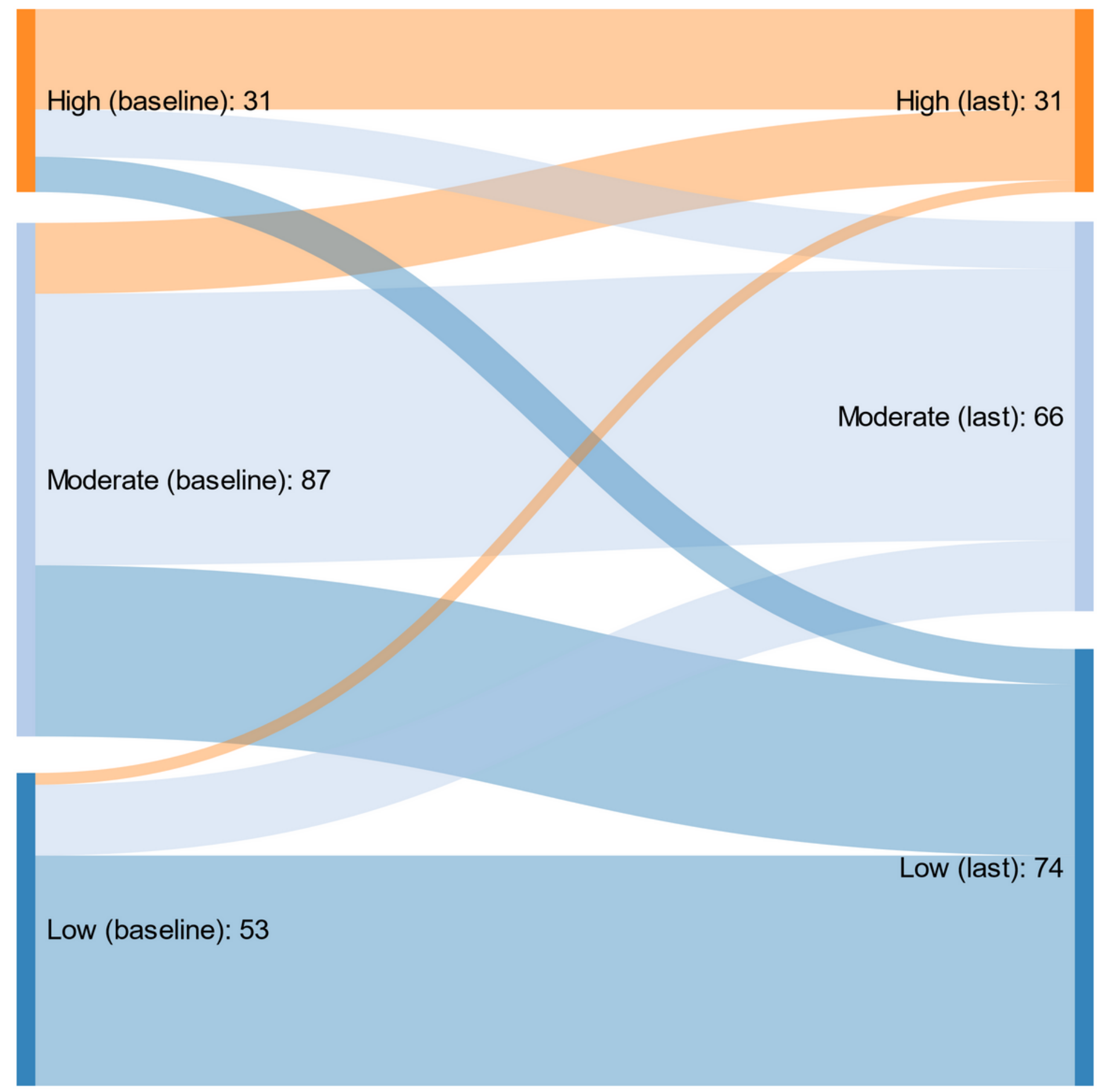

\section{Figure 1}

title: Patients' substance use severity index (SUSI) changes from baseline to the last substance use measurement ( $N=171$ ) Legends: The figure displays the SUSI changes from baseline (left (baseline)) to the last substance use measurement (right (last)) for patients with at least two substance use measurements. Patients were divided into three SUSI levels at baseline and the last substance use measurement: low (SUSI 
$<0.2$ (dark blue)), moderate (SUSI 0.2 - 0.4 (light blue)), and high (SUSI > 0.4 (orange)). The SUSI ranges from 0 to 1 , where 0 indicates no substance use and 1 indicates daily substance use for all substances (cannabis, amphetamines, cocaine, opioids, benzodiazepines, and alcohol).

\section{Supplementary Files}

This is a list of supplementary files associated with this preprint. Click to download.

- AdditionalFile1.docx 